\title{
Gender and energy: is there a Northern perspective? ${ }^{[1]}$
}

\author{
Joy Clancy \\ Technology and Development Group, University of Twente, Post Box 217, 7500 AE Enschede, the Netherlands \\ E-mail: j.s.clancy@tdg.utwente.nl
}

Ulrike Roehr

LIFE e.V. -- FrauenUmweltNetz, Hohenstaufenstrasse 8, D-60327 Frankfurt, Germany

E-mail: roehr@life-online.de

\section{Introduction}

Studies of issues around gender and energy focus primarily on women in the South and there is a growing literature in the field (see for example, [Cecelski, 1995] and [Parikh, 1995]). In the Northern industrialised countries, despite the extensive literature on gender, science and technology (see for example, the International Bibliography on Gender, Science and Technology on the WIGSAT Internet site [WIGSAT, undated]), energy has not been a focal area of gender analysis (nor has gender been incorporated in energy analysis). Energy, in a Northern context, is seen as gender-neutral; women and men are regarded as equal in their uses of and views about energy, hence policies accurately reflect the needs and wishes of the population. However, there have recently appeared two documents which indicate that this assumption of gender neutrality might be a misconception [Clancy et al., 2001; Roehr, 2001]. This paper aims to test the hypothesis of gender neutrality in energy in the North by reviewing the available evidence.

First, a word of explanation about the term "the North". This term, which was popularised by the Brandt Report [Brandt, 1980], was used originally to cover the industrialised countries belonging to the Organisation for Economic Cooperation and Development (OECD), although we have extended the membership to include the Eastern European countries, known as the Accession countries. It is not meant in a geographical sense, since it includes Australia and New Zealand. However, there is no simple, agreed, unambiguous term to describe the complex reality of a group of countries that differ in degrees over a range of characteristics, from climate to culture. However, the terms "North" and "South" have the advantage that they are value-free, as compared to, say, "developed" and "developing". The term "the North" should be seen as convenient shorthand but keeping in mind that it is not a 
homogeneous entity even in terms of energy demand, supply and use.

\section{Should we take gender into account in the energy sector in the North?}

Should we take gender and energy issues into account in the North? Social justice arguments of fairness or equality would imply that all women and men have the right to the equal enjoyment of socially valued goods, opportunities, resources and rewards and equal participation in decision-making about those goods. Energy is a commodity which both provides services and offers job opportunities. Therefore, women and men should, on equality principles, have equal opportunities not only to make use of energy but also to be able to participate in making choices about energy both at the policy level and in their own lives. A starting-point for assessing whether or not there is a need to take gender into account in the energy sector in the North could be to determine first whether or not there are gender differences in terms of attitudes towards energy in the North.

The term "gender" is used here deliberately rather than "sex". The term "gender" refers to socially constructed roles of women and men rather than biologically determined differences. These gender roles of men and women, with their accompanying responsibilities, constraints, opportunities, and needs, are defined by a particular society. Gender roles are learnt by children as part of their socialisation process. The roles change over time and vary widely within and across cultures. Men and women play different roles in Northern societies, although at first glance these may not be so clearly defined as in the South. However, research shows that women, while remaining part of the paid workforce longer, still continue to carry the main responsibility for household tasks and child care in Northern societies [Blossfeld and Drobnic, 2001; Sarmiento, undated]. If this division of household tasks does exist then it would not be unreasonable to assume that there may also exist a division of responsibilities for decisions related to energy within the household. Identifying such gender differences is important if effective messages about energy conservation are to be addressed to the appropriate household member.

To determine whether or not energy has a gender dimension in the North four questions can be usefully posed to form an analytical framework ${ }^{[2]}$. Are the lives of women and men affected differently in terms of the energy forms they use? If gender differences towards energy exist, are women and men able to exercise choices that reflect those differences about energy? Do women and men in the North have different preferences for energy policy? Are women able to make effective contributions as academics, as activists and as workers in the energy sector? The fourth question specifically focuses on women. It is well established that women are in a minority in engineering- and technology-related fields (see, for example, [EC, 2000] and [Science, 1995]), so it is not unreasonable to assume that the energy sector is the same: women are in a minority. The issue then becomes whether or not this minority position affects their ability to contribute effectively and to achieve personal goals (be those goals implementation of particular policies or career aspirations).

\section{Gender and household energy in the North}

There is little published information about how energy impacts differently on the lives of women and men in the North. For example, a detailed household energy survey in New Zealand which set out to identify the technical and behavioural factors that determine energy use did not disaggregate household members by gender [Stoecklein, 1997]. The United Nations Department for Economic and Social Affairs (UN-DESA) also did not take gender as a factor into account in its assessment of trends in household energy consumption [Dzioubinski and Chipman, 1999]. However, demographic evidence related to household income would suggest that there are likely to be gender issues in energy and so gender is not something to ignore. In the North, there are more women than men below the poverty line; for example, in the USA $15.4 \%$ of women and $12 \%$ of men live below the poverty line $\mathrm{e}^{[3]}$ [Reddy, 2000]. Women with low incomes are disproportionately found as heads of households either as single parents, or, owing to their greater longevity than men, living alone at pensionable age.

How does poverty impact on energy choices? Young children and older people have special requirements to reduce their vulnerability to illness. In the UK, households spending more than $20 \%$ of their income on fuel are classified as "living in fuel poverty". In 1991, 7 million households (36\% of total) in the UK suffered from fuel poverty [Boardman, 1998, quoted in Reddy, 2001]. Heating/cooling and cooking for people on low incomes can be problematic if they have a restricted choice of energy forms: electricity is expensive, and solid fuel produces smoke which has negative health impacts. It should also not be forgotten that some areas of the North are at present war-torn or recovering from strife, for example, Bosnia-Herzegovina, Kosovo, and Chechnya. Many of these areas have severe winters with a high demand for heating and cooking fuel. Women have to search for fuel and are exposed to the sorts of dangers not unfamiliar to women in the South. Physical and psychological violence against women has been reported, for example, experiencing sniper fire to gather fuel in Sarajevo [ESG and CSD-NGO WC, 2001].

People on low incomes often live in housing with poor insulation and frequently use second-hand or old equipment with poor energy efficiency. People on low incomes often have to pay for their electricity and gas through pre-payment systems which can be charged on a higher unit cost basis than that fixed for households with monthly billing systems. All these factors contribute to high energy costs for people on low incomes. From just this brief analysis and the demographics mentioned above, it could reasonably be concluded that there will be more women than men living in energy poverty in the North.

Research in Germany has identified differences based 
on age in attitudes towards energy. Elderly women tend to consume less energy than younger women [EPSECC, 1997; Preisendoerfer, 1999]. Energy conservation approaches also differ in the two categories: elderly women save energy by changing their behaviour patterns, for example, cooking less, whereas young women tend to opt for technological options. Preisendoerfer [1999] suggests that these differences in attitudes to energy reduction strategies can be explained by socialisation processes. Women of pensionable age grew up in a time of austerity and on the basis of these experiences they may have undergone a socialisation process which emphasises frugality, and the need for frugality will be reinforced if they are on low incomes. Younger women have grown up with a greater familiarity with new technologies and hence more readily adopt strategies that involve using new pieces of equipment.

There appears to be a difference in energy consumption related to marital status and whether or not the woman is in paid employment. In the Netherlands, the Bureau of Statistics found, in a survey on environmental attitudes and behaviour, that in two-income households (i.e., with a working female partner), energy use per capita was greater than in households where the female partner did not work or was a working woman living alone [Broek et al., 1997]. On the basis of research from the United States, it was concluded that mothers in paid employment need to juggle work and household responsibilities, frequently leading to a higher consumption of resources; time pressures increasingly entail the use of energy-intensive cars, not public transport, while transporting children to school and sports, shopping and carrying out other household errands owing to their geographical dispersion [Sarmiento, undated]. Research in Germany found when comparing the households of single men and single women a distinct difference in the types of appliances owned. Men own more communication appliances, such as answering machines, mobile telephones, and computers, than women do, while women own more appliances associated with household chores, such as washing machines, dryers, refrigerators, than men do.

Transport use has significant implications for energy consumption. A detailed national travel survey in Sweden (quoted in [Grover et al., 1999]) took gender as one of the key variables. The findings in the survey included strong correlations with income and energy use, as well as strong correlations, within income groups, between energy consumption and gender. Low-income groups tended to use public transport more and had lower annual energy consumption than higher income groups. Within income groups, women used less energy than men. This finding is not only related to work patterns but also to leisure activities: women tend to pursue leisure activities closer to home than men.

Since the oil crises of the 1970s, government policies directed at household energy use have encouraged a more efficient use of energy [Dzioubinski and Chipman, 1999]. Research in Germany would certainly indicate that at the household level there is a distinct gender division of re- sponsibilities towards translating these policies into practice [Doerr, 1993; Buko, 1995; Schwartau-Schuldt, 1990]. Men are mainly responsible for technical decisions and investments in thermal insulation of homes, boilers, and hot water installations. In contrast to this, women have the responsibility for energy conservation by reducing their use of electric appliances, such as washing machines and dishwashers, and encouraging the rest of the family to do likewise.

\section{Gender dimensions of energy policy}

Can gender differences towards energy policies in industrialised countries be identified? There is very little published statistical data. A secondary analysis of public opinion data collected between 1973 and 1979 from 115 national, state, and local surveys in the United States was published by Farhar et al. [1979; 1980]. Findings showed little discernible gender differences in energy policy preferences, although women had a slightly stronger preference than men did for energy conservation and a slightly greater antipathy than men did to nuclear power. More recent data on gender and energy preferences exist, but have not been analysed and published.

Perceptions of gender differences in energy choices tend to be that women are considered to favour "soft" energies (that is, renewables) and men "hard" energies (that is, fossil fuels and nuclear) [Longstreth et al., 1989]. A study in the USA, by Longstreth and her co-workers, started from the hypothesis that women more than men favour soft energy paths and found that there were only slight differences between women and men when opting for soft energy paths. Similar findings were also reported as part of a study conducted for the European Commission. A number of female and male energy professionals were surveyed on priorities for energy research. The majority of respondents considered that there were no differences between men and women in their priorities [Clancy et al., 2001]. Those who did see differences agreed with the hypothesis that women favour soft energy paths. Women scientists within the European Union, interviewed as part of the study by Clancy et al. [2001], did hold a strong preference for research in renewable energy and energy conservation. They also considered that social issues should also be integrated into energy research. Longstreth et al. [1989] found that women more than men favoured wind energy, while men were more positive than women towards solar energy and hydropower.

In some respects these findings are surprising. It is not unreasonable to assume that if one has a strong awareness of environmental protection it would be matched with a predisposition towards environmentally-friendly technologies, which would include renewable energy technologies. Women are found in surveys to have a greater concern for the environment. For example, a survey in Japan of consumer awareness of and behaviour response to global environmental problems showed that at least in people over 40, women had a stronger sense than men of environmental awareness (quoted in [Grover et al., 1999]). Similar findings in Germany are reported by Preisendoer- 
fer [1999]. The survey in Japan also showed how this environmental awareness was translated into behaviour within the household. Women were more inclined than men to turn off lights in rooms not in use ( $45 \%$ compared to $41 \%$ ), adjust air-conditioners to moderate temperatures (40\% compared to $34 \%$ ) and use public transport in preference to cars.

Distinct gender differences are found in attitudes towards nuclear power. A survey conducted in Sweden in the late 1990s found $60 \%$ of young men in favour of the long-term use of nuclear power, while $80 \%$ of young women were against its long-term use [Puranen, 2000]. Men who were in favour of nuclear power were concerned about the economic aspects, its value for Sweden, and its safety. They considered it environmentally more beneficial than coal and oil. Pro-nuclear women mentioned that nuclear power is cheap and clean but did not refer to safety aspects. For women who are against nuclear power it is the safety aspect that is the major concern. Clancy et al. [2001] also found that women researchers in the nuclear industry opted for research in safety aspects of nuclear energy, as well as stressing its medical applications. Puranen's survey also found that $63 \%$ of men had no objection to waste being stored in their own municipality as opposed to $34 \%$ of women. A gender difference in respect of attitudes to nuclear power was founded linked to the respondent's educational level. The higher a woman's education level, the more likely she is to reject nuclear energy use. In contrast, men's positive attitudes towards nuclear energy increase with their educational level [Puranen, 2000]. Public opinion is influenced by not only safety issues but also market and economic issues, and anti-nuclear feelings tend to be strongest in those areas which do not have nuclear power stations. However, studies in the USA show that even where jobs were at stake women still tended to favour environmental quality more than men [Longstreth et al., 1989].

\section{Influencing the energy sector}

\subsection{Women setting political agendas}

In Section 2, we argued the case that women and men have the right not only to enjoy the equal benefit of, in this case, energy but also to have equal participation in decision-making about energy services. However, despite the social changes since the 1960s related to women's emancipation, women and men still do not play equal roles in public life; men continue to dominate both in political spheres and in science and engineering. Men's contribution to the energy sector is clear but do women play any distinctive role either as policy-makers or employees? This section reviews the progress women are making in the energy sector.

There is no doubt that there are many women in the North active in the political arena around energy, either as activists (for example, the Plutonium Free Future Women's Network [econippon, undated] - known as Rainbow Serpent and based in Japan - and Mama-86 [Mama86, undated] - which is based in the Ukraine) or as politicians (for example, in New Zealand, the MP Janette
Fitzsimmons is a prominent energy activist and the coleader of the Green Party). In terms of women's influence on energy policy, it is rather heartening to see that, within the European Parliament, one-third of the Committee for Industry, External Trade, Research and Energy is female [Clancy et al., 2001]. Women were also active in raising energy issues in events leading up to and around the World Summit on Sustainable Development (see, for example, [Operaocha, 2001; de Melo Branco and Roehr, 2002]).

Women have been leading activists in the anti-nuclear movement. For example, Rainbow Serpent has campaigned to demand that governments shift their investments and subsidies away from nuclear and fossil fuels and towards safe, renewable energy systems. Women do seem more strongly represented in the renewable energy field than in conventional energy fields. However, women are not a homogeneous group and it should be no surprise to find groups of pro-nuclear women. There is a very active network of women working in the nuclear industry (WIN, see [WIN, undated]) who lobby vigorously for non-military uses of nuclear energy.

Women have complained that when the movement became "professionalised", men took over the strategic positions and so weakened women's opportunities for influencing political agendas [Roehr, 2001].

Women are particularly active in NGOs that support women in the South (for example, ENERGIA [ENERGIA, undated], the international network on gender and energy).

\subsection{Women working in the energy sector}

There is a small but growing band of women working in the energy sector. However, the sector suffers from the perception that it offers a professional career dominated by 50-year-old males, particularly in the technical areas [Clancy et al., 2001]. Data which are representative for OECD countries in general can be seen in statistics for Australia: women make up $20 \%$ of the work force in the electricity, gas and water sector but occupy less than $5 \%$ of technical posts [OSW, 1999]. For example, the share of female technical staff in the energy industry in Germany is around $6 \%$, in decision-making positions $4 \%$, and in the top management less than $1 \%$ [HoppenstedtAnalyse, 2000]. Women in the energy industry work mainly in administration, sales, finance, catering, and personnel. The energy sector has a highly masculine image and perceptions are that the type of work done in the industry involves heavy labour. This is regarded as a significant barrier to female participation. However, in recent years automation has reduced the need for significant inputs of muscular labour.

Energy companies are beginning to recognise that it is not merely a question of recruiting women to help fill professional vacancies, but also one of women bringing particular benefits to the workplace. Women's skills can be complementary to men's, and hence lead to a more balanced and efficient organisation. Recent initiatives to recruit more women include the ENEQO [sydkraft, undated] project within the electricity industry in Europe, 
which aims to advance equal opportunities by promoting the positive benefits employing women brings to the working environment. In Canada, the oil and gas sector is promoting a diverse workforce and adopting the approach of recognising the contributions people make as capable individuals rather than as members of designated groups [Dowse et al., 1999].

For many women the experience of being part of a small minority working in the energy sector can create a sense of isolation. Sometimes this leads them to abandoning their careers; sometimes they leave to set up businesses with other women (see, for example, Box 1 which describes Windfang, a women's cooperative producing electricity from wind energy in Germany).

\section{Towards gender equality in the energy sector in the North}

In this paper, we have set out to test the null hypothesis that in the North gender is energy-neutral both in terms of use and in terms of supply-side options. On the basis of existing evidence we can say that there would appear to be a distinct gender dimension in the way women and men's lives are affected by energy use while the evidence about gender differences in preferences for particular primary energy forms as a basis of supply is, with the exception of nuclear energy, equivocal.

The use of energy in the North is influenced by geography and by income level. The research on transport use from Sweden, a seemingly homogeneous and egalitarian society, indicates that large disparities in consumption based on gender do exist. An understanding of the factors which influence consumption patterns and their consequences is important in order to develop appropriate policies that more closely reflect the reality of people's lives and where responsibilities for energy consumption really lie. For example, there is a gender dimension to energy conservation: it is women who implement energy-saving policies but have not influenced the production of goods, including their energy efficiency, used within the household. Also, exhortations not to use tumble driers and change cooking practices presuppose a desire to behave in an environmentally-friendly way, which, evidence suggests, women already do. However, such exhortations overlook the practicalities of whether or not the physical construction of houses allows putting these options into practice (for example, whether or not an apartment has the space for a drying-room or gas supplies to a dwelling are possible).

The provision of energy-related data on a gender-disaggregated basis would not only bring out these types of contradictions in energy policy but also make it possible to be more definite about whether or not there are gender differences on the supply side. The provision of genderdisaggregated data could be done relatively easily, at least within Europe. The European Commission biennially surveys European citizens on their attitudes to a key range of policy issues, including energy. At present, the data is not published on a gender-disaggregated basis. A simple adjustment could provide a wealth of information about

\section{Box 1. Windfang: women making energy for themselves [Delfs, 2000]}

A company (Windfang) owned by 200 women working on co-operative principles operates a $450 \mathrm{~kW}$ wind turbine, which is feeding into the national grid to the north of Hamburg in northern Germany. The company grew out of an initiative by three women who had grown disillusioned with the unsupportive male-dominated working environment they had encountered in the energy sector. Although most of the founding members were technically-oriented, the group is now multidisciplinary and has members of all ages, from students to women professionals, and from a broad range of disciplines such as theatre and economics. Of importance to most of the members is the peer support gained from working within a group of women. Not all of the women work in the company but those who don't have provided some of the finance for the company and derive satisfaction from pragmatically working towards a cleaner environment. In addition, the way in which decision-making is carried out within the company is an important principle. The women opted for a democratic structure which allows all members to elect the steering committee and board, while major decisions are taken at a general assembly. One of Windfang's objectives is to increase the work experience of women in energy projects and thus improve their chance of a good job in the energy sector. Having gained confidence while working in a supportive environment, several of the founding members have now moved on to set up their own businesses or have found jobs in the renewable energy industries.

how men and women within the European Union view energy policy and choices. The availability of this information to policy-makers is vital, since as we have argued, women and men should, on the basis of equity, have equal opportunities not only to make use of energy but also to be able to participate in making choices about energy both at the policy level and in their own lives.

Women are clearly under-represented as professionals in the energy sector [Clancy et al., 2001]. However, is it significant if parity does not exist in the numbers of men and women in the energy sector? From an economic perspective, a number of human resource directors in energy industries certainly consider that their industry is missing out by not tapping into a pool of female talent. A response based on social justice might be: probably not, if women have access to other areas of the economy where they can make contributions to policy-making and implementation, with financial rewards at least commensurate with those available to men. On the other hand, a political approach that recognises that each gender has its own norms and values would respond: yes it is, since a sector dominated by one gender will tend to make decisions which reflect the norms and values of that gender, hence masculine- 
dominated industries will reflect male agendas in terms of both the policies they pursue and the work environment.

Increasing the numbers of women in the energy sector is only one way of changing the nature of the energy sector. Employing men who also subscribe to "feminine" values can also lead to transformations. In a survey of women researchers in the European Union, Clancy and her colleagues [2001] reported that a number of the older women interviewed commented on a perceptible change in attitudes and behaviour amongst young men now working in the energy sector compared to their older male colleagues. Young men are becoming more and more environment-conscious and socially aware, and do not always subscribe to the "masculine culture of work".

How can we encourage more women into the energy sector? There are examples of creative approaches that are needed to make the field more attractive. For example, in Germany, young women are being motivated to study energy with courses specially designed for women ${ }^{[4]}$. At the University of Bielefeld, women in electrical engineering are offered a course in "energy consulting and marketing" which prepares them for a career in management within the energy sector; while at the University of Wilhelmshaven there are special courses on energy economics.

However, it is a question of more than getting women into the energy sector; it is also a question of keeping women there. It is not only an issue of finding the subject stimulating but the working environment has to be conducive to remaining there. Although data specifically relating to the energy industry is difficult to find, the career problems faced by women in engineering and science are well documented (see, for example, [EC, 2001]). A current affairs study in Germany found that barriers to women remaining in employment include the male-dominated culture at the workplace, traditional hierarchies and nontransparency of promotion processes [Accenture, 2002]. Similar findings are reported by Clancy et al. [2001], with the experiences of women in respect of promotion worse in academic research institutions than in industry. A cultural change, flexible working conditions, involvement of men in child care and whole-day nursery are strategies which could contribute to bringing women into the management of the energy industry and hopefully keep them there.

Networking can play an important part in supporting women in their work. There are a small number of national networks; for example, in Germany, there is "Energiefrauen" (Women in Energy), a national informal network of more than 150 women students and professionals. The petroleum sector has recently established a Women Petroleum and Energy Club.

Awareness is slowly increasing that there is a gender dimension to the energy sector in the North. However, we still lack a more in-depth analysis of gender differences related to energy use and energy production. As a first step there is a need for gender-differentiated published data which we consider will be able to contribute to gen- der justice in energy policy.

\section{Notes}

1. This paper is based on two pieces of work by the authors: a study by Clancy et al. (2001) entitled Gender and Energy -- Women's Concerns in Energy: Background and State of the Art prepared for the European Commission Research Directorate, and a background paper by Roehr (2001), "Gender and Energy in the North" prepared for an expert workshop "Gender Perspectives for Earth Summit 2002: Energy, Transport, Information for Decision Making" held in Berlin, Germany, 10-12 J anuary 2001.

2. This approach is based on that of the European Commission in its gender mainstreaming policy: to encourage research by women, on women and for women which uses the framework: research for women, by women, and on women [EC, 1999].

3. Poverty is a relative state. Many in the South would not consider women classified as "poor" by Northern standards as living in poverty. In terms of their material possessions, this might well be true. However, in terms of having opportunities and the ability to make choices which impact on their and their families' health and creativity, poor women in the North also face barriers because of their low income relative to others in their society. It is important to remember that poverty in the North also has a race dimension. For example, in the USA, African-Americans make up approximately $12 \%$ of the population but form $28 \%$ of the poor. Poverty in the North means people are not afforded the dignity and respect of wealthier members of society.

4. Motivation includes the slogan "Women swimming against the stream". This is a clever pun in German since the word for "stream" and "electricity" is the same: strom.

\section{References}

Accenture, 2002. Women and Energy. Perspectives for Female Executives in the Energy Economy (www.strom.de)

Blossfeld, H.-P., and Drobnic, S., (eds.), 2001. Careers of Couples in Contemporary Societies: From Male-Breadwinner to Dual Earner Families, Oxford, Oxford University Press.

Boardman, B., 1998. "Energy efficiency and fuel poverty", presented at PRASEG Annual Conference, 5 November.

Brandt, W., 1980. North-South: a Programme for Survival, The Brandt Report, Independent Commission on Development Issues, MIT Press, ISBN 0-262-52059-1.

Broek, A. van den, Knulst, W.P., and Niggebrugge, F.D.E., 1997. Trends in de tijdsbesteding van de Nederlandse bevolking 1975-1995, Werkdocument 41, Sociaal Cultureel Planbureau (SCP).

Buko, 1996. "Zwischen sparstruempfen und gigabytes -- der oekologen lust, der frauen frust: eine feministische kritik zur studie 'Nachhaltiges Deutschland')", in Forum entwicklungspolitischer Aktionsgruppen, Heft 201/96 (Feminist Critiques on the Study "Sustainable Germany").

Cecelski, E.W., 1995. "From Rio to Beijing: engendering the energy debate", Energy Policy, 23(6), pp. 561-571

Clancy, J.S., Stienstra, M., Gregory, J., and Cornland, D., 2001. Gender and Energy -Women's Concerns in Energy: Background and State of the Art, Working Paper 1, study carried out for the European Commission Research Directorate.

Delfs, C., 2000. "Case-study: women producing electricity from renewables: from 'project' to 'market': the 'Windfang' project in Germany", ENERGIA News, Vol. 3, No. 1.

Dowse, S., Horton, K., Lele, D., and Sherk, S., 1999. Women in Canada's Oil and Gas Sector, Report prepared for the Canadian International Development Agency's Oil and Gas Sector Programme, Pakistan.

de Melo Branco A., and Roehr, U., 2002. "The WSSD and its results regarding gender and energy", ENERGIA News, Vol. 5, No. 4, pp. 1-2.

Doerr, G., 1993. "Die oekologisierung des oikos" (The ecologization of the oikos), in Schultz, I., (ed.), GlobalHaushalt. Globalisierung von Stoffstroemen -- Feminisierung von Verantwortung, Frankfurt/M., Verlag fuer interkulturelle Kommunikation.

Dzioubinski, O., and Chipman, R., 1999. Trends in Consumption and Production: Household Energy Consumption, United Nations Department for Economic and Social Affairs (DESA) Discussion Paper No. 6 ST/ESA/1999/DP.6. UN, New York, http://www.un.org/esa/papers.htm.

ENERGIA, undated. http://www.energia.org

ENERGIA Support Group and CSD-NGO Women's Caucus (ESG and CSD-NGO WC), 2001. "Gender perspectives on energy for CSD-9", a position paper prepared for the 9th Session of the Commission on Sustainable Development, http://www.energia.org econippon, undated. http://www.econippon.org/en/orgs/pff/pff.html.

Environmental Policy, Social Exclusion and Climate Change Research Co-operation (EPSECC), 1997. Environmental Policy, Social Exclusion and Climate Change Research Co-operation Work Packages 2: Data Analysis.

European Commission, 1999. Women in Science -- Mobilising Women to Enrich European Research, Colosimo, A., and Dewandre, N., (eds.), www.cordis.lu/improving/src/women_com.htm

European Commission, 2000. Science Policies in the European Union: Promoting Excellence 
through Mainstreaming Gender Equality: a Report from the ETAN Expert Working Group on Women and Science, Luxembourg, Office for Official Publications of the European Communities.

Farhar, B.C., Weis, P., Unseld, C.T., and Burns, B.A., 1979. Public Opinion about Energy: A Literature Review, SERI/TR-53-155, J une.

Farhar, B.C., Unseld C.T., Vories, R., and Crews, R., 1980. "Public opinion about energy", Ann. Rev. Energy, 5, pp. 141-172.

Farhar, B.C., and Coburn, T.C., 2000. Market Assessment of Residential Grid-Tied PV Systems in Colorado, NICH Report No. TP-550-25283, 229 pp.

Grover, S., Flenley, C., and Hemmati, M., 1999. Gender and Sustainable Consumption: Bridging Policy Gaps in the Context of Chapter 4, Agenda 21 -- Changing Consumption and Production Patterns, Report for the United Nations Commission on Sustainable Development, 7th Session, April 1999, http://www.unedforum.org

Hoppenstedt-Analyse, 2000. Frauen im Management 1999 (Women in Management 1999). Branchenanalyse 1, Hoppenstedt-Verlag.

Longstreth, M., Turner, I.., Topliff, M., and lams, D., 1989. "Support for soft and hard path American energy policies: does gender play a role?", Women's Studies International Forum, Vol. 12, No. 2, pp. 213-226

Mama-86, undated. http://www.mama-86.kiev.ua/

Office of the Status of Women (OSW), 1999. Women in Australia 99, Commonwealth Government of Australia, http://www.osw.dpmc.gov.au/index.htm

Operaocha, S., 2001. "Genderising the energy debate at CSD9", ENERGIA News, Vol. 4 , No. 3, pp. 5-6.

Parikh, J.K., 1995. "Gender issues in energy policy", Energy Policy, Vol. 23, No. 9, pp. 745-754, September.
Preisendoerfer, P., 1999. Umwelteinstellungen und Umweltverhalten in Deutschland: Empirische Befunde und Analysen auf der Grundlage der Bevoelkerungsumfragen "Umweltbewusstsein in Deutschland 1991-1998", Herausgegeben vom Umweltbundesamt (Environmental Attitudes and Environmental Behaviour in Germany), Leske und Budrich, Opladen.

Puranen, B., 2000. Young Women and Men: Increasingly Alike? http://www.bikupan.se/young/

Reddy, A.K.N., 2000. "Energy and social issues", in World Energy Assessment, United Nations Development Programme.

Roehr, U., 2001. "Gender and energy in the North", Background Paper for the International Conference Gender Perspectives for Earth Summit 2002: Energy, Transport, Information for Decision Making, Berlin, 10-12 J anuary, www.frauenumweltnetz.de/veroeffentlichungen.html Sarmiento, S., undated. Household, Gender and Travel, www.fhwa.dot.gov/ohim/womens/ chap3.pdf.

Schwartau-Schuldt, S., 1990. "Oekostress im haushalt", in Study Group Domestic Science, (ed)., Haushaltstraeume: Ein J ahrhundert der Technisierung und Rationalisierung im Haushalt: Arbeitsgemeinschaft Hauswirtschaft ( $\mathrm{Hg}$.), Verlag Langewiesche Nachf., Koenigstein ("Eco stress in the household", in Household-dreams: a Century of Mechanisation and Rationalisation in the Household)

Stoecklein, S., 1997. "Teenage daughters and other unpredictables", Build, February-March, pp. $36-38$

sydkraft, undated. http://www1.sydkraft.se/eneqo/home.htm

WIGSAT, undated. http://www.wigsat.org

WIN, undated. http://www.win-global.org

\section{Subscribe now to Energy for Sustainable Development}

Send a cheque in favour of

"Energy for Sustainable Development" to:

Executive Editor

Energy for Sustainable Development

25/5, Borebank Road, Benson Town

Bangalore-560 046, India

Subscription rates

\begin{tabular}{|l|l|l|}
\hline \multirow{2}{*}{ India } & \multicolumn{1}{|c|}{ Individual } & Institutional \\
\cline { 2 - 3 } & Rs. 120 & Rs. 240 \\
\hline Other developing countries & US\$ $4 *$ & US\$ $8^{*}$ \\
\hline Industrialised countries & US\$ $70^{*}$ & US\$ $70^{*}$ \\
\hline
\end{tabular}

* or equivalent amount in any convertible currency.

Subscriptions may be sent by cheque payable in India or remitted by wire transfer.

For wire transfers, the remittance should be made payable to:

Account No. CA-105, TIDE Account Energy for Sustainable Development

Canara Bank, Indian Institute of Science branch, Bangalore, India

Destination Swift Code: CNRBINBBLFD (Canara Bank, Foreign Division, Bangalore)

through any one of the following accounts:

04-427-255 with Bankers Trust Company, New York, Swift Code: BKTRUS33

0001-120066-001 with Canara Bank, London, Swift Code: CNRBGB2L

499080630-4711 with Dresdner Bank AG, Frankfurt, Swift Code: DRESDEFF

16-187211-1121 with Union Bank of California International, Tokyo, Swift Code: BOFCJPJT

Please make sure to send us an e-mail or fax containing details of subscriber's name,

address and category of subscription. 